\title{
CARACTERIZAÇÃO TECNOLÓGICA DE MATERIAIS ESTÉREIS COM ELEVADOS TEORES DE PPC E FÓSFORO DA MINA DE ALEGRIA*
}

Herynson Nunes Nascimento ${ }^{1}$ Antônio Eduardo Clark Peres ${ }^{2}$ Lamartine Silva Freitas ${ }^{3}$ Marcos Gomes Vieira ${ }^{3}$

\section{Resumo}

Este trabalho investigou a possibilidade de gerar informações, para subsidiar a Samarco no aproveitamento futuro de materiais considerados estéreis pelo elevado teor de PPC e P. Foram feitos testes de caracterização tecnológica, simulando em bancada os processos de beneficiamento da Samarco Mineração. Observou-se que as amostras estudadas requererem maior consumo energético na moagem primária, implicando em uma menor produtividade. Essas apresentam índices inferiores de recuperação na deslamagem e flotação convencional. Entretanto apresentaram boa cinética de flotação e o grau de liberação do quartzo maior que $90 \%$ para todas as frações granulométricas. As amostras também apresentaram baixa produtividade na moagem secundária e granulometria grosseira para o atendimento da meta de Blaine praticada atualmente. Não foi possível a obtenção da especificação final de sílica no concentrado após a remoagem. Os testes de sedimentação não indicaram problemas. Foram realizados também ensaios em escala de bancada para separação magnética utilizando Minimag (WHIMS) que provaram que os materiais estudados apresentam comportamento paramagnético.

Palavras-chave: Britagem; Moagem; Flotação; Separação magnética.

\section{TECHNOLOGICAL CHARACTERISTICS OF WASTER MATERIALS WITH HIGH PERCENTEGE LOI AND P}

\section{Abstract}

This study addressed the possibility of generating information to support Samarco's decision on the future concentration of materials presenting high contents of LOI and P. Technological characterization tests were performed, simulating at bench scale the beneficiation processes at Samarco. It was observed that the samples studied require increased energy consumption in the primary grinding, resulting in lower productivity. These have lower recovery rates in desliming and conventional flotation. However, the flotation kinetics was good and the liberation degree of quartz in all size fractions was higher than $90 \%$. The samples showed low productivity in secondary crushing and coarse particle size to meet the target of Blaine currently practiced. Unable to obtain the final specification of silica in the concentrate after regrinding. The tests did not show sedimentation problems. Tests were also conducted in a bench scale for magnetic separation using Minimag (WHIMS), which proved that the studied materials exhibit paramagnetic behavior.

Keywords: Crushing; Grinding; Flotation; Magnetic separation.

\footnotetext{
Chefe de Departamento, Samarco Mineração S/A. Mariana, MG, Brasil.

Professor Universidade Federal de Minas Gerais, Belo Horizonte, MG, Brasil.

Analista de Processo, Samarco Mineração S/A. Mariana, MG, Brasil.

Gerente de Processo, Samarco Mineração S/A, Mariana, MG, Brasil.
}

* Submetido ao 15 Simpósio Brasileiro de Minério de Ferro, 15 a 18 de setembro de 2014, Belo Horizonte, MG, Brasil. 


\section{INTRODUÇÃO}

A viabilidade de extração do minério de ferro não é definida apenas pelos teores mínimos de ferro $(\mathrm{Fe})$ e por suas classes de frações granulométricas, mas também pelos máximos de impurezas $\left(\mathrm{SiO}_{2}, \mathrm{Al}_{2} \mathrm{O}_{3}, \mathrm{P}, \mathrm{PPC}\right.$ etc.) que são rigidamente controladas. Isso requer que, mesmo para minérios de alto teor considerados friáveis, o processo seja controlado de tal forma que os produtos gerados atendam às especificações relacionadas ao nível de impurezas.

Para a garantia da produção, tanto quantitativa como qualitativa, é necessário, muitas vezes, que as empresas de mineração desenvolvam suas reservas minerais, alinhadas as melhorias no seu processo industrial de beneficiamento.

A preocupação em manter e aumentar os volumes de produção tem levado cada vez mais ao aproveitamento de materiais estéreis na mineração, pelo emprego de novas tecnologias de beneficiamento de "minérios" com teores mais pobres e com maior presença de contaminantes. Sem dúvida alguma, para a verificação da possibilidade do aproveitamento desses materiais, faz-se necessária a caracterização tecnológica dos mesmos (caracterização mineralógica, granulométrica, química e ensaios tecnológicos específicos para um determinado emprego) [1].

Alinhada a busca pelo desenvolvimento de novas tecnologias e aumento de capacidade, a Samarco terá um acréscimo de produção da ordem de 8 milhões de toneladas de pelotas ano, com a construção do terceiro concentrador e de mais uma usina de pelotização, passando dos atuais de 23,5 para 31,5 milhões de toneladas de pelotas por ano em 2014. Novos projetos de ampliação já estão contemplados em seu plano de negócios.

O constante aumento de capacidade implica em busca de um melhor aproveitamento de reserva. O melhor aproveitamento de reserva é dependente de um maior conhecimento dos recursos geológicos através do suporte amostral (quantidade e profundidade dos furos de sonda), de teores de corte mais baixos para uma ou mais variáveis controladas pelo planejamento de mina e maximização da recuperação de ferro [2].

Nesse contexto caracterização de minérios é uma etapa fundamental para o máximo aproveitamento de um recurso mineral. É um ramo especializado aplicado ao beneficiamento de minérios e que estuda aspectos específicos da mineralogia dos minérios. As informações obtidas através dessa análise são utilizadas para o desenvolvimento e a otimização de processos.

A importância do processamento de materiais considerados estéreis por presença de contaminantes, mas com teores de ferro razoáveis, se torna fundamental com a tendência da indústria da mineração de, com o passar do tempo, lavrarem minérios com teores cada vez mais pobres. Isso ocorre porque os minérios mais nobres estão se exaurindo.

Após a avaliação do complexo minerador, a Samarco identificou a potencialidade de ampliar sua reserva através da incorporação de minérios com maiores teores de contaminantes, principalmente PPC e P. Assim, haverá a necessidade de avaliar o processo de tratamento atual considerando as novas características do run of mine.

Tendo em mente o aproveitamento desse tipo de material e a sustentabilidade das operações de mina e concentração, neste trabalho são descritas as características físicas, químicas e mineralógicas a fim de caracterizar esse tipo de estéril objetivando fornecer informações que subsidiem o desenvolvimento de novas tecnologias e a escolha de técnicas de concentração e processamento mineral adequado às características do material.

* Submetido ao 15은 Simpósio Brasileiro de Minério de Ferro, 15 a 18 de setembro de 2014, Belo Horizonte, MG, Brasil. 


\section{MATERIAIS E MÉTODOS}

Para elaboração deste trabalho foram compostas 2 amostras de aproximadamente $1800 \mathrm{~kg}$ referentes a minérios de Alegria Norte e Alegria Sul. Considerando a nova reserva, a Samarco possui 3,08 bilhões de toneladas de minério de ferro. A formação ferrífera é cortada em minério e estéril por 2 atributos: fósforo no concentrado $(\mathrm{Pc})$ ou PPCc. Para a Samarco é considerado minério toda formação ferrífera que estiver dentro da cava com teores de $\mathrm{Pc}<0,097 \%$ e PPCc $<7,7 \%$. Em contrapartida, será considerado estéril material com teor de Pc $>0,097 \%$ ou com teor de PPCc $>7,7 \%$.

Neste caso, tem-se três grandes grupos de estéril: (i) estéril que foi cortado apenas pelo Pc (Pc $>0,097$ e o PPCc $<7,7$ ); (ii) estéril que foi cortado apenas pelo PPCc (Pc < 0,097 e PPCc > 7,7); (iii) estéril que foi cortado pelo Pc e pelo PPCc $(\mathrm{Pc}>0,097$ e PPCc $>7,7)$.

As amostras estão no primeiro grupo, são "minérios" cortados apenas por fósforo. Para o processo de beneficiamento, o teor de fósforo é pouco impactante sendo que as grandes dificuldades serão com os materiais hidratados, com PPC maior do que $6 \%$.

Como referência usou-se amostra do minério atualmente processado designada como amostra remanescente.

A caracterização feita para as amostras valerá para os minérios hidratados, materiais com o mesmo nível de PPC, mas com fósforo mais baixo. A amostra de Alegria Norte representa aproximadamente 69 milhões de toneladas dentro da cava, enquanto que a amostra de Alegria Sul representa 19 milhões toneladas.

Os ensaios tecnológicos foram divididos em duas etapas: (i) ensaios em bancada dos processos de pré-moagem e moagem primária, deslamagem, flotação, remoagem e espessamento, simulando, assim, o processo das Usinas I e II da Samarco Mineração; (ii) ensaios envolvendo concentração magnética utilizando Minimag (WHIMS) no produto da moagem primária e no underflow da deslamagem.

\section{RESULTADOS}

A figura 1 mostra a comparação das análises granulométricas das duas amostras de minérios estudadas, através do percentual de $+3 / 8$ " (material que alimentaria 0 circuito II da britagem), bem como o percentual passante em 100\# Tyler. Observase, tanto pela figura 1, como pela tabela 1, que a amostra Norte é mais grosseira que a amostra Sul, sendo que a amostra Remanescente é mais grosseira que a amostra Sul e mais fina que a amostra Norte.

* Submetido ao $15^{\circ}$ Simpósio Brasileiro de Minério de Ferro, 15 a 18 de setembro de 2014, Belo Horizonte, MG, Brasil. 


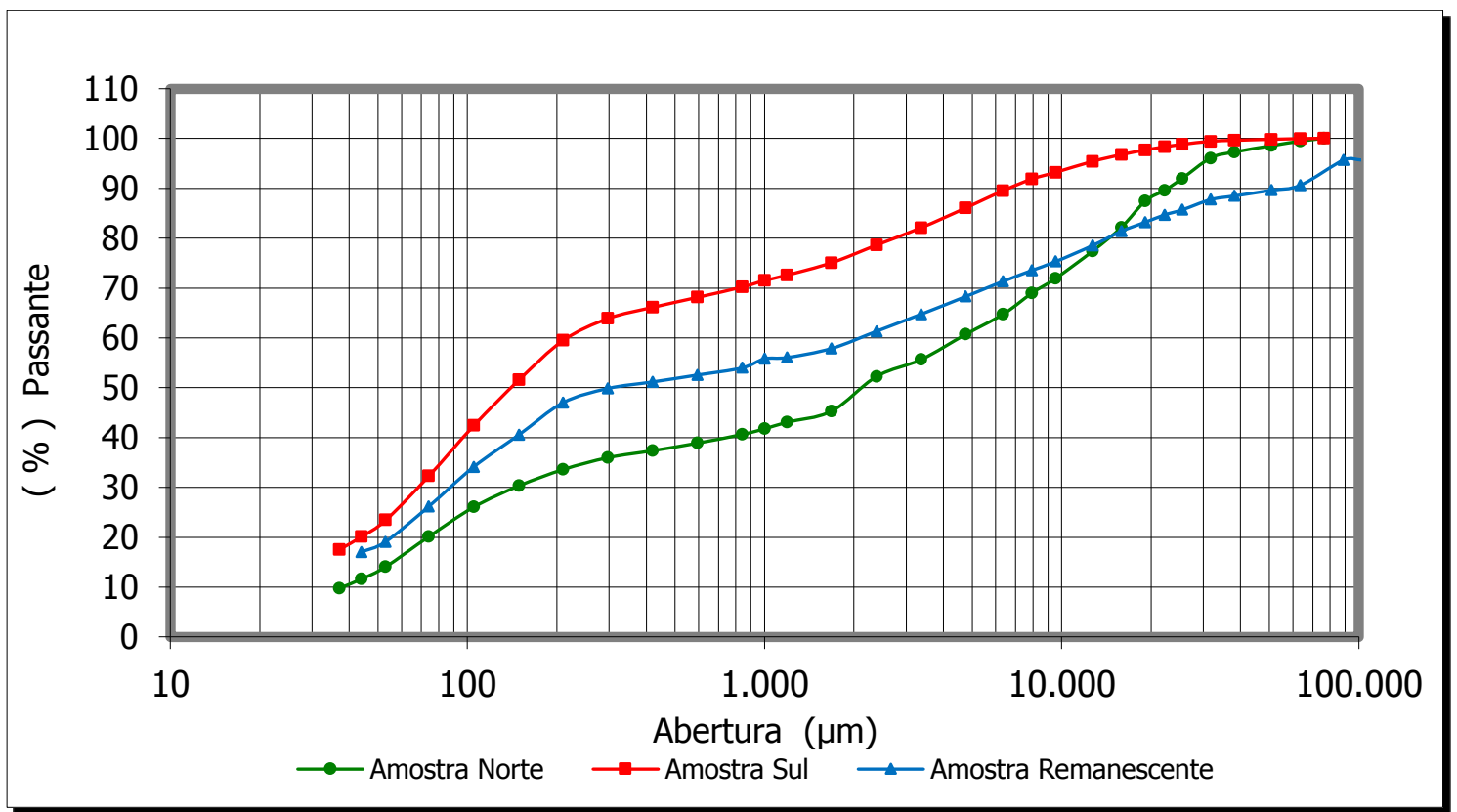

Figura 1. Análise granulométrica do ROM.

Tabela 1. Comparações entre \%+3/8", \%-100\# e química do ROM

\begin{tabular}{|c|c|c|c|c|c|c|c|c|}
\hline Amostra & $+3 / 8 "$ & $\%-100 \#$ & $\% \mathrm{Fe}$ & $\% \mathrm{SiO}_{2}$ & $\% \mathrm{Al}_{2} \mathrm{O}_{3}$ & $\% \mathrm{P}$ & $\% \mathrm{PPC}$ & $\% \mathrm{MnO}$ \\
\hline Norte & 28,09 & 30,34 & 43,31 & 31,14 & 0,61 & 0,09 & 5,97 & 0,15 \\
\hline Sul & 6,82 & 51,58 & 38,42 & 39,1 & 0,71 & 0,07 & 5,09 & 0,01 \\
\hline Remanescente & 24,67 & 40,56 & 45,3 & 31,64 & 0,52 & 0,05 & 2,93 & 0,03 \\
\hline
\end{tabular}

As curvas de percentagem retida em $150 \mu \mathrm{m}$ em função da energia aplicada no eixo pinhão dos minérios estudados estão apresentadas na figura 2. A curva obtida com a amostra Remanescente foi inserida como referência.

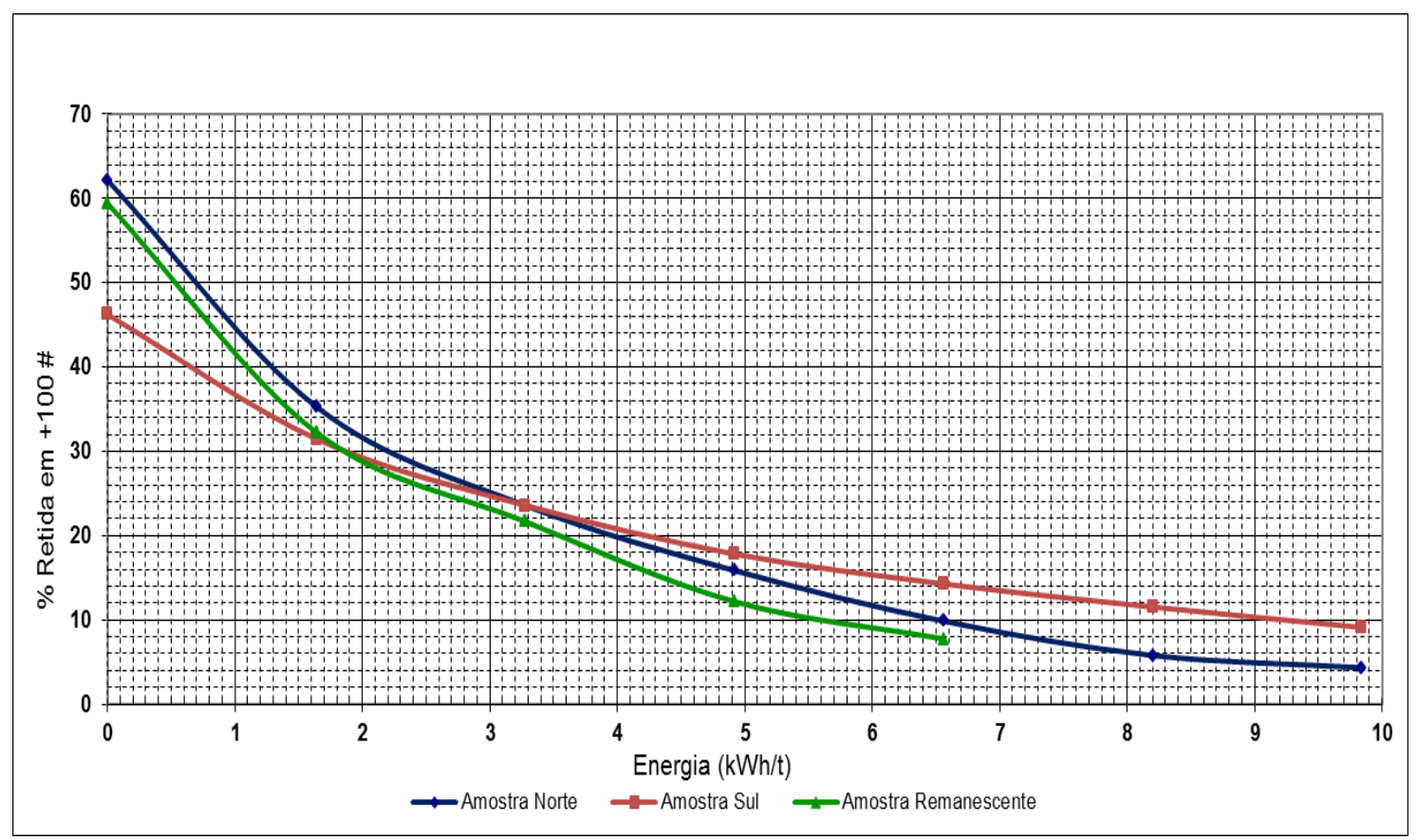

Figura 2. \%+100\# em função da energia aplicada no eixo pinhão.

* Submetido ao 15 Simpósio Brasileiro de Minério de Ferro, 15 a 18 de setembro de 2014, Belo Horizonte, MG, Brasil. 
Pela análise da figura 2, uma vez adequada a granulometria de alimentação do concentrador pela britagem, a amostra que representa o minério de Alegria Norte possui uma cinética de quebra mais favorável se comparado à amostra Sul, porém ambas são menos favoráveis que aquela da amostra Remanescente.

Após a realização de deslamagem em três etapas, foram realizadas análises químicas do underflow e overflow, conforme visualizado na tabela 2.

Tabela 2. Análise química do underflow e overflow da deslamagem

\begin{tabular}{|c|c|c|c|c|c|c|}
\hline AMOSTRA & $\% \mathrm{Fe}$ & $\% \mathrm{SiO} 2$ & $\% \mathrm{Al} 2 \mathrm{O} 3$ & $\% \mathrm{P}$ & $\% \mathrm{PPC}$ & $\% \mathrm{MnO}$ \\
\hline Rem underflow & 45,18 & 32,57 & 0,3 & 0,042 & 2,4 & 0,04 \\
\hline Rem overflow & 51,26 & 16,16 & 3,44 & 0,12 & 6,75 & 0,09 \\
\hline Alegria Norte underflow & 41,59 & 34,44 & 0,42 & 0,077 & 5,34 & 0,16 \\
\hline Alegria Norte overflow & 51,45 & 14,59 & 1,9 & 0,138 & 9,47 & 0,17 \\
\hline Alegria Sul underflow & 36,08 & 43,31 & 0,51 & 0,082 & 4,4 & 0,01 \\
\hline Alegria Sul overflow & 51,37 & 13,29 & 2,85 & 0,157 & 10,36 & 0,03 \\
\hline
\end{tabular}

Observando a tabela 2 pode-se ver que as frações de overflow das três amostras possuem percentagem de ferro na faixa de $51 \%$, no entanto, levando em consideração o underflow das amostras, Alegria Sul possui uma percentagem muito inferior principalmente em relação à amostra Remanescente. Com relação às impurezas, é possível perceber que após a deslamagem as amostras de Alegria Norte e Alegria Sul possuem altos teores de P e PPC.

A tabela 3 apresenta as fases mineralógicas presentes em cada uma das amostras estudadas. As amostras caracterizadas possuem um percentual muito inferior de hematita especular se comparadas à Amostra Remanescente.

Tabela 3. Mineralogia total (percentual em peso)

\begin{tabular}{|c|c|c|c|c|c|c|c|c|}
\hline Amostra & $\begin{array}{c}\text { Hematita } \\
\text { Especular }\end{array}$ & $\begin{array}{c}\text { Hematita } \\
\text { Porosa }\end{array}$ & Goethita & Magnetita & $\begin{array}{c}\text { Quartzo } \\
\text { Inteiro }\end{array}$ & $\begin{array}{c}\text { Quartzo } \\
\text { Misto }\end{array}$ & Outros & Total \\
\hline Remanescente & 20,48 & 30,99 & 17,26 & 2,34 & 28,25 & 0,67 & 0,01 & 100 \\
\hline $\begin{array}{c}\text { Amostra Norte } \\
<28 \# \text { a }>100 \#\end{array}$ & 0,26 & 35,33 & 39,04 & 1,69 & 22,82 & 0,68 & 0,18 & 100 \\
\hline $\begin{array}{c}\text { Amostra Norte } \\
<100 \# \text { a }>325 \#\end{array}$ & 0,36 & 25,23 & 21,58 & 0,89 & 50,38 & 1,56 & 0 & 100 \\
\hline $\begin{array}{c}\text { Amostra Sul } \\
<28 \# \text { a }>100 \#\end{array}$ & 0,83 & 30,50 & 38,81 & 1,48 & 27,95 & 0,43 & 0 & 100 \\
\hline $\begin{array}{c}\text { Amostra Sul } \\
<100 \# \text { a }>325 \#\end{array}$ & 3,73 & 23,67 & 17,32 & 1,74 & 52,12 & 1,41 & 0 & 100 \\
\hline
\end{tabular}

O grau de liberação do quartzo por faixa granulométrica pode ser visualizado na tabela 4. Para ambas as amostras, o grau de liberação do quartzo é superior a $90 \%$ em todas as frações analisadas. Esses resultados demonstram provável facilidade para obtenção de sílica no concentrado da fase de flotação mecânica.

* Submetido ao 15 Simpósio Brasileiro de Minério de Ferro, 15 a 18 de setembro de 2014, Belo Horizonte, MG, Brasil. 
Tabela 4. Grau de liberação do quartzo por fração

\begin{tabular}{|c|c|c|c|c|c|}
\hline AMOSTRA & $+100 \#$ & $\begin{array}{c}-100 \# \\
+150 \#\end{array}$ & $\begin{array}{c}-150 \# \\
+200 \#\end{array}$ & $\begin{array}{c}-200 \# \\
+325 \#\end{array}$ & $-325 \#$ \\
\hline Amostra Norte & 90,7 & 98,2 & 96,3 & 99,2 & 99,7 \\
\hline Amostra Sul & 98 & 99,3 & 98,7 & 99,4 & 100 \\
\hline
\end{tabular}

Os resultados globais da deslamagem e flotação são visualizados na tabela V.

Tabela 5. Resultados globais deslamagem e flotação

\begin{tabular}{|c|c|c|c|c|c|c|c|c|}
\hline \multirow{2}{*}{ AMOSTRA } & \multicolumn{6}{|c|}{ DESLAMAGEM } & \multicolumn{6}{|c|}{ FLOTAÇÃO } \\
\cline { 2 - 9 } & $\mathrm{RP}$ & $\mathrm{RM}$ & $\begin{array}{c}\% \mathrm{Fe} \\
\text { alim } \\
\text { calc. }\end{array}$ & $\begin{array}{c}\% \mathrm{Fe} \\
\text { conc. }\end{array}$ & $\begin{array}{c}\% \mathrm{SiO}_{2} \\
\text { conc. }\end{array}$ & $\begin{array}{c}\% \mathrm{Fe} \\
\text { rej. }\end{array}$ & $\mathrm{RP}$ & $\mathrm{RM}$ \\
\hline Remanescente & 92,05 & 91,81 & 45,98 & 65,35 & 2,35 & 11,69 & 63,91 & 90,45 \\
\hline Amostra Norte & 87,17 & 82,21 & 41,69 & 61,86 & 2,38 & 13,75 & 58,08 & 86,17 \\
\hline Amostra Sul & 88,58 & 85,66 & 36,11 & 63,21 & 2,35 & 13,19 & 46,66 & 80,52 \\
\hline
\end{tabular}

As curvas da percentagem retida em $44 \mu \mathrm{m}$ em função da energia aplicada no eixo pinhão dos minérios caracterizados estão apresentadas na figura 3. Foi colocada como referência a amostra Samarco Remanescente. Observa-se que a curva do minério de Alegria Sul é similar a curva do minério de Alegria Norte, sendo ambos com o consumo específico previsto de $\mathrm{kWh} / \mathrm{t}$ acima da amostra Remanescente. $\mathrm{O}$ consumo específico previsto industrialmente para o minério de Alegria Sul é de $14,4 \mathrm{kWh} / \mathrm{t}$, o que gera uma produtividade de $12,73 \times 10^{6}$ t/ano.

Para a amostra de Alegria Norte o consumo específico médio previsto para o minério é de $15,6 \mathrm{kWh} / \mathrm{t}$ gerando uma produtividade de $11,75 \times 10^{6} \mathrm{t}$ /ano, enquanto o consumo específico da amostra Samarco Remanescente é de 10,8kWh/t sendo a produtividade de $16,97 \times 10^{6}$ t/ano. Para o cálculo do consumo de energia no eixo pinhão foram consideradas em todas elas $88 \%$ passante em $44 \mu \mathrm{m}$.

O cálculo de produtividade considerado foi:

Produtividade $=[(4200 \times 6 \times 0,92) /($ Consumo específico $)] \times(24 \times 365 \times 0,95 \times 0,95)$

* Submetido ao 15 Simpósio Brasileiro de Minério de Ferro, 15 a 18 de setembro de 2014, Belo Horizonte, MG, Brasil. 


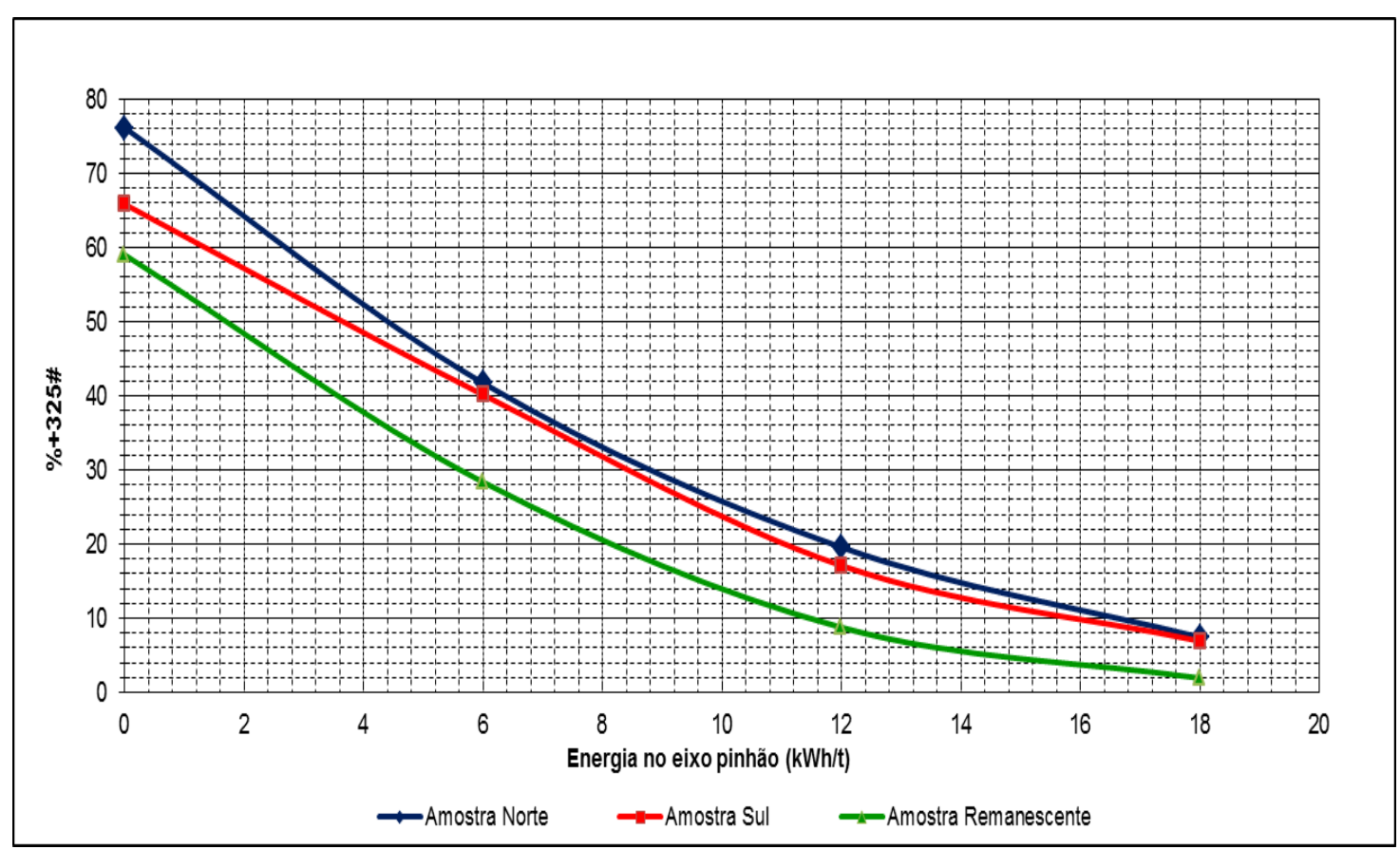

Figura 3. Curvas da \%+325\# em função da energia aplicada no eixo pinhão.

A figura 4 apresenta as curvas de Blaine em função da energia aplicada no eixo pinhão. A curva do Blaine da Amostra Norte e da Amostra Sul indica que a geração de superfície é muito maior do que da amostra Remanescente. Considerando $12 \mathrm{Kwh} / \mathrm{t}$, tem-se para Alegria Norte $80 \%$ passante em $325 \#$ e $2500 \mathrm{~cm}^{2} / \mathrm{g}$ de Blaine. Para Alegria Sul temos $83 \%$ passante em $325 \#$ e $2600 \mathrm{~cm}^{2} / \mathrm{g}$ de Blaine, enquanto para a amostra Remanescente temos $92 \%$ passante em $325 \#$ e $1900 \mathrm{~cm}^{2} / \mathrm{g}$ de Blaine. Isso implica em granulometria grosseira para amostras de Alegria Norte e Sul para $\mathrm{o}$ atendimento a meta de Blaine, ou Blaine elevado para atendimento à meta de granulometria.

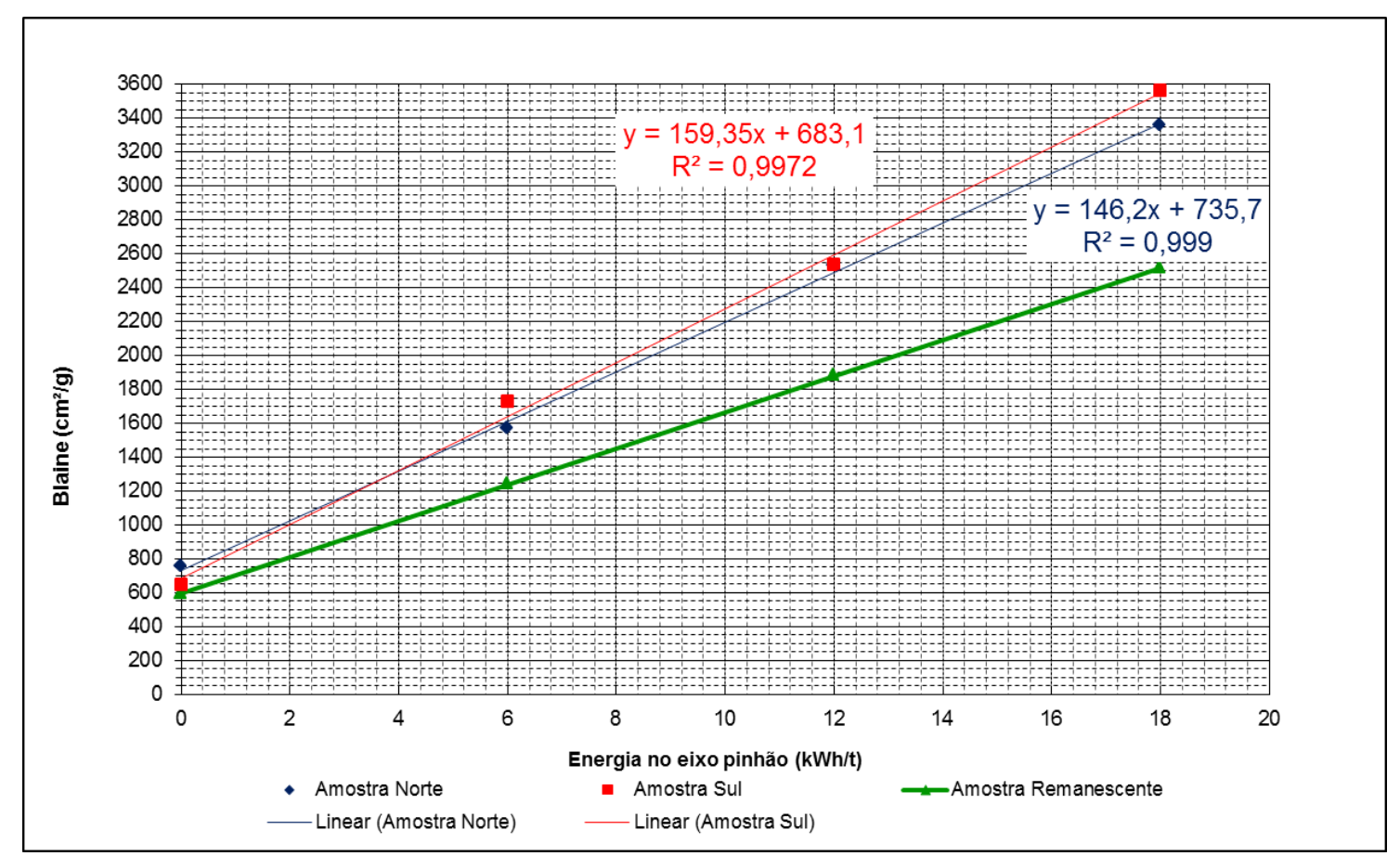

Figura 4. Curvas do Blaine em função da energia aplicada no eixo pinhão.

* Submetido ao $15^{\circ}$ Simpósio Brasileiro de Minério de Ferro, 15 a 18 de setembro de 2014, Belo Horizonte, MG, Brasil. 
Foram realizados testes de flotação com o minério remoído para $88 \%$ passante em 325\# Tyler. O objetivo foi verificar a possibilidade de obtenção de teor de sílica no concentrado após remoagem. Os resultados dos testes estão apresentados na tabela 4.

Tabela 6. Testes de flotação após remoagem

\begin{tabular}{|c|c|c|c|c|c|c|c|c|}
\hline \multirow{2}{*}{ Amostra } & $\begin{array}{c}\text { Amido } \\
\text { (g/t) }\end{array}$ & $\begin{array}{c}\text { Amina } \\
\mathbf{( g / t )}\end{array}$ & $\begin{array}{c}\text { \%Fe } \\
\text { alim } \\
\text { calc. }\end{array}$ & $\begin{array}{c}\text { \%Fe } \\
\text { conc. }\end{array}$ & $\begin{array}{c}\text { \%SiO } \\
\text { conc. }\end{array}$ & \%Fe rej. & RP & RM \\
\hline \multirow{2}{*}{ Norte } & 700 & 50 & 61,83 & 62,23 & 2 & 60 & 81,94 & 82,47 \\
\cline { 2 - 10 } & $\mathbf{6 0 0}$ & $\mathbf{3 0}$ & $\mathbf{6 1 , 6 6}$ & $\mathbf{6 2 , 0 6}$ & $\mathbf{2 , 0 9}$ & $\mathbf{5 9 , 0 6}$ & $\mathbf{8 6 , 7 9}$ & $\mathbf{8 7 , 3 5}$ \\
\hline \multirow{2}{*}{ Sul } & 700 & 50 & 62,24 & 62,62 & 1,65 & 60,67 & 80,39 & 80,88 \\
\cline { 2 - 9 } & $\mathbf{6 0 0}$ & $\mathbf{3 0}$ & $\mathbf{6 2 , 3 4}$ & $\mathbf{6 2 , 7}$ & $\mathbf{1 , 7 1}$ & $\mathbf{5 9 , 9}$ & $\mathbf{8 6 , 9 3}$ & $\mathbf{8 7 , 4 3}$ \\
\hline
\end{tabular}

Analisando a tabela 6 percebe-se que nas duas amostras não foi possível a obtenção de especificação final de $\mathrm{SiO}_{2}$ no concentrado do minério, mesmo elevando a concentração de amina para $50 \mathrm{~g} / \mathrm{t}$. É possível perceber também que para uma quantidade inferior de reagentes é os rejeitos são melhores, refletindo em maiores recuperações em peso e metálica. É importante salientar que as amostras foram remoídas para $88 \%$ passante em 325\# Tyler, condição que não será alcançada no circuito de remoagem atual do concentrador.

Foram realizados testes de concentração magnética para quatro amostras de materiais estéreis com elevado teor de PPC e P das minas de alegria norte e sul (duas amostras por mina). Essas amostras foram subdivididas em dois materiais: deslamados (representando o material que alimentação a flotação mecânica) e moídos (representando o produto da moagem primária). O objetivo é analisar uma possível rota de processo para os materiais estudados de Alegria Norte e Alegria Sul. Os resultados são apresentados nas tabelas 7 a 10.

A tabela 7 mostra a análise química da concentração magnética da Amostra Norte deslamada, onde se observa o enriquecimento do minério após o teste, passando a percentagem de ferro de $41,59 \%$ para $46,54 \%$ no concentrado. Apesar de haver uma redução nos teores de $\mathrm{SiO} 2$, não houve redução significativa dos patamares de PPC, quando comparado o material alimentado com o concentrado final.

Tabela 7. Análise química da concentração magnética para a Amostra Norte deslamada

\begin{tabular}{|c|c|c|c|c|c|c|}
\hline $\begin{array}{c}\text { AMOSTRA - } \\
\text { Norte } \\
\text { Deslamada }\end{array}$ & $\% \mathrm{Fe}$ & $\% \mathrm{SiO}_{2}$ & $\% \mathrm{Al}_{2} \mathrm{O}_{3}$ & $\% \mathrm{P}$ & $\% \mathrm{PPC}$ & $\% \mathrm{MnO}$ \\
\hline Alimentação & 41,59 & 34,44 & 0,42 & 0,077 & 5,34 & 0,16 \\
\hline Rejeito & 33,92 & 44,08 & 0,44 & 0,087 & 6,63 & 0,16 \\
\hline Médio & 33,94 & 46,77 & 0,44 & 0,087 & 3,91 & 0,16 \\
\hline Concentrado & 46,54 & 27,45 & 0,42 & 0,088 & 5,24 & 0,15 \\
\hline
\end{tabular}

A tabela 8 apresenta a análise química da concentração magnética da Amostra Norte moída. Os resultados demonstram enriquecimento do material onde a percentagem de ferro na alimentação passa de 43,31\% para 49,19\% no concentrado e a percentagem de $\mathrm{SiO}_{2}$ e PPC diminuem de $31,14 \%$ para $23,26 \%$ e de $5,97 \%$ para $5,52 \%$, respectivamente. Não houve redução significativa do percentual de $\mathrm{P}$.

* Submetido ao 15 Simpósio Brasileiro de Minério de Ferro, 15 a 18 de setembro de 2014, Belo Horizonte, MG, Brasil. 
Tabela 8. Análise química da concentração magnética para a Amostra Norte moída

\begin{tabular}{|c|c|c|c|c|c|c|}
\hline $\begin{array}{c}\text { AMOSTRA - } \\
\text { Norte Moída }\end{array}$ & $\% \mathrm{Fe}$ & $\% \mathrm{SiO}_{2}$ & $\% \mathrm{Al}_{2} \mathrm{O}_{3}$ & $\% \mathrm{P}$ & $\% \mathrm{PPC}$ & $\% \mathrm{MnO}$ \\
\hline Alimentação & 43,31 & 31,14 & 0,61 & 0,09 & 5,97 & 0,15 \\
\hline Rejeito & 37,23 & 39,61 & 0,62 & 0,096 & 6,16 & 0,16 \\
\hline Médio & 38,11 & 38,11 & 0,64 & 0,100 & 6,38 & 0,16 \\
\hline Concentrado & 49,19 & 23,26 & 0,54 & 0,09 & 5,52 & 0,14 \\
\hline
\end{tabular}

A tabela 9 mostra os resultados da concentração magnética para a Amostra Sul deslamada onde visualizamos um aumento na percentagem de $\mathrm{Fe}$ de aproximadamente $17 \%$ da alimentação para o concentrado. Além disso, a percentagem de $\mathrm{SiO} 2$ foi reduzida em praticamente 23\% demonstrando um enriquecimento após a concentração magnética. Observou-se também redução da percentagem de PPC de $4,4 \%$ para $3,70 \%$ e de $\mathrm{P}$ de $0,082 \%$ para $0,061 \%$.

Tabela 9. Análise química da concentração magnética para a Amostra Sul deslamada

\begin{tabular}{|c|c|c|c|c|c|c|}
\hline $\begin{array}{c}\text { AMOSTRA - } \\
\text { Sul } \\
\text { Deslamada }\end{array}$ & $\% \mathrm{Fe}$ & $\% \mathrm{SiO}_{2}$ & $\% \mathrm{Al}_{2} \mathrm{O}_{3}$ & $\% \mathrm{P}$ & $\% \mathrm{PPC}$ & $\% \mathrm{MnO}$ \\
\hline Alimentação & 36,08 & 43,31 & 0,51 & 0,082 & 4,40 & 0,01 \\
\hline Rejeito & 29,87 & 52,39 & 0,45 & 0,063 & 4,29 & 0,02 \\
\hline Médio & 34,47 & 45,12 & 0,54 & 0,074 & 4,88 & 0,01 \\
\hline Concentrado & 53,07 & 19,82 & 0,45 & 0,061 & 3,70 & 0,02 \\
\hline
\end{tabular}

A tabela 10 ilustra a análise química da concentração magnética para a Amostra Sul moída. Levando em consideração todas as amostras testadas, essa representa os melhores resultados tendo elevado o teor de Fe de $38,42 \%$ para $57,87 \%$ e redução de $\mathrm{SiO}_{2}$ de $39,10 \%$ para $12,98 \%$. Percebe-se também a redução das impurezas presentes, sendo o PPC reduzido de $5,09 \%$ para $3,72 \%$, percentagem de $\mathrm{P}$ reduziu de $0,07 \%$ para $0,063 \%$ e o $\mathrm{Al}_{2} \mathrm{O}_{3}$ reduziu de $0,71 \%$ para $0,48 \%$.

Tabela 10. Análise química da concentração magnética para a Amostra Sul moída

\begin{tabular}{|c|c|c|c|c|c|c|}
\hline $\begin{array}{c}\text { AMOSTRA - } \\
\text { Sul Moída }\end{array}$ & $\% \mathrm{Fe}$ & $\% \mathrm{SiO}_{2}$ & $\% \mathrm{Al}_{2} \mathrm{O}_{3}$ & $\% \mathrm{P}$ & $\% \mathrm{PPC}$ & $\% \mathrm{MnO}$ \\
\hline Alimentação & 38,42 & 39,10 & 0,71 & 0,07 & 5,09 & 0,01 \\
\hline Rejeito & 30,88 & 49,72 & 0,79 & 0,076 & 5,16 & 0,01 \\
\hline Médio & 36 & 41,71 & 0,78 & 0,083 & 5,78 & 0,07 \\
\hline Concentrado & 57,87 & 12,98 & 0,48 & 0,063 & 3,72 & 0,01 \\
\hline
\end{tabular}

Analisando os resultados globais das Amostras Norte e Sul após a concentração magnética, percebe-se a tendência de ambas serem magnéticos. Os resultados obtidos demonstram que a Amostra Sul é mais fortemente paramagnética se comparada à Amostra Norte e, além disso, a separação magnética após a primeira moagem apresenta melhores resultados que aquela com as amostras deslamadas.

\section{DISCUSSÃO}

As amostras estudadas requerem maior consumo energético na moagem primária, implicando em uma menor produtividade. Essas apresentam índices inferiores de

* Submetido ao 15 Simpósio Brasileiro de Minério de Ferro, 15 a 18 de setembro de 2014, Belo Horizonte, MG, Brasil. 


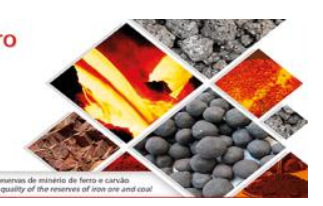

recuperação na deslamagem e flotação convencional. Entretanto apresentaram boa cinética de flotação e o grau de liberação do quartzo maior que $90 \%$ para as frações granulométricas maiores que 100\# e inferiores a 325\# Tyler.

As amostras estudadas apresentaram baixa produtividade na moagem secundária $\left(12,73 \times 10^{6}\right.$ t/ano para Amostra Sul e para a Amostra Norte $11,75 \times 10^{6}$ t/ano). Em relação ao Blaine, considerando $12 \mathrm{Kwh} / \mathrm{t}$, tem-se para Alegria Norte $80 \%$ passante em $325 \#$ e $2500 \mathrm{~cm}^{2} / \mathrm{g}$. Para Alegria Sul temos $83 \%$ passante em $325 \#$ e $2600 \mathrm{~cm}^{2} / \mathrm{g}$, resultados muito superiores aos praticados atualmente na Samarco. Isso implica em granulometria grosseira para atendimento da meta de Blaine, ou Blaine elevado, para atendimento da meta de granulometria.

Não foi possível a obtenção da especificação final de sílica no concentrado após a remoagem. Os testes de sedimentação não indicaram problemas nas etapas de espessamento de lama, rejeito e concentrado.

Com os ensaios em escala de bancada para separação magnética utilizando Minimag (WHIMS) no produto da moagem primária e no underflow da deslamagem, foi possível avaliar a possibilidade de melhorar a concentração dos materiais. As separações magnéticas provaram a susceptibilidade magnética inerente a este tipo de material. Pelos resultados obtidos, inserir uma concentração magnética após a moagem primária enriqueceria substancialmente a alimentação da flotação, além de desbastar grande parte da sílica presente.

\section{CONCLUSÃO}

Os resultados obtidos irão contribuir com informações que podem subsidiar a Samarco no aproveitamento futuro de materiais considerados estéreis pelo elevado teor de PPC e P (aproximadamente 90 milhões de toneladas) das minas de Alegria Sul e Norte.

Destaca-se como ganho de primordial relevância do trabalho os resultados obtidos através da caracterização tecnológica, pois estes demonstram ser possível através do mix adequado de ROM na mina e pelo emprego de novas tecnologias no beneficiamento, como a separação magnética, adequar "minérios" com teores mais pobres e com maior presença de contaminantes, às características químicas e físicas exigidas pelo pellet feed Samarco.

\section{Agradecimentos}

Os autores agradecem à CAPES/PROEX, CNPq e FAPEMIG pelo apoio financeiro ao PPGEM e à SAMARCO pelo financiamento do projeto.

\section{REFERÊNCIAS}

1 Reis EL. Caracterização de resíduos provenientes da planta de beneficiamento do minério de manganês sílico-carbonatado da RDM - Unidade Morro da Mina. Dissertação de Mestrado, Programa de Pós-Graduação em Engenharia Mineral, Universidade Federal de Ouro Preto. 2005, 124p.

2 Vieira MG. Produção de um pellet feed a partir da concentração do rejeito da flotação mecânica da Samarco. Dissertação de Mestrado, Curso de Pós-Graduação em Engenharia Metalúrgica e de Minas, Universidade Federal de Minas Gerais. 2008, 90 p.

* Submetido ao 15ํ Simpósio Brasileiro de Minério de Ferro, 15 a 18 de setembro de 2014, Belo Horizonte, MG, Brasil. 